\title{
A VERY RARE CASE OF TORSION OF A NON-GRAVID UTERUS DUE TO LARGE INTRAMURAL MYOMA
}

Neelam Nalini' ${ }^{1}$, Bijeta ${ }^{2}$, Jitendra Kumar Singh ${ }^{3}$

\section{HOW TO CITE THIS ARTICLE:}

Neelam Nalini, Bijeta, Jitendra Kumar Singh. "A Very Rare Case of Torsion of a Non-Gravid Uterus due to Large Intramural Myoma". Journal of Evolution of Medical and Dental Sciences 2015; Vol. 4, Issue 16, February 23; Page: 2846-2849, DOI: $10.14260 /$ jemds/2015/410

\begin{abstract}
Torsion of ovary especially dermoid is very common but torsion of uterus is a rare phenomenon. Torsion of gravid uterus has been reported in many journals but torsion of non-gravid uterus is rarest of the rare. Causes usually associated are big myomas involving uterine body and sparing cervix, and sometimes uterine anomalies and adnexal masses. Preoperative diagnosis is very difficult and usually diagnosis is made during laparotomy. Here we are going to discuss a case of nongravid uterine torsion in a 47 year old lady due to big intramural fibroid involving uterine body but sparing the cervix. Cervix became thin, elongated and acted like a pedicle/pivot around which torsion took place. The patient was admitted with acute abdominal pain and shock.
\end{abstract}

KEYWORDS: Cervix, ovarian cyst, pedicle, laparotomy.

INTRODUCTION: Torsion of uterus is defined as rotation of the uterus along its longitudinal axis by more than 45 degrees $^{1}$. Most of the cases of uterine torsion have been described in a gravid uterus and is a rare phenomenon in non-gravid uterus. ${ }^{2}$ In a non-gravid uterus the torsion is usually associated with the presence of big myomas, and sometimes due to adnexal masses and uterine anomaly. ${ }^{3}$ It is a potential life threatening condition and warrants urgent surgical intervention. Preoperative diagnosis is usually difficult and can be missed on a routine ultrasound. In ultrasound it is usually mistaken with twisted ovarian cyst or twisted pedunculated fibroid.

CASE: A 47 year old lady $\left(\mathrm{P}_{2+0}\right.$, both by caesarean section) presented in our hospital with complaints of severe pain lower abdomen for two days and no passage of urine for the last 24 hours. She had menorrhagia for one year for which she was on medical treatment on and off and her cycles were regular. She was in agony due to severe pain at the time of examination. She had cold clammy skin, moderate pallor, pulse was 136/minute, blood pressure was 90/60 $\mathrm{mmHg}$, chest was clear, on cardiovascular examination $\mathrm{S}_{1} \mathrm{~S}_{2}$ heard and there was tachycardia. Per abdominal examination revealed a very tender mid line lump of about 18 weeks size, occupying hypogastrium, and slightly encroaching both iliac fossa. It was firm in consistency with well-defined borders (However difficult to palpate due to tenderness).

In per speculum examination cervix was pulled up, smooth and difficult to visualise. On per vaginal examination a lump of about 18 weeks size felt, uterus could not be felt separately. A detailed assessment was not possible due to tenderness. The patient was shifted for ultrasound. Transabdominal ultrasound showed an ovoid soft tissue lesion in pelvis measuring $17.3 \times 11.7 \times 12.1$ cms (Approx.) with heterogenous echogenicity along with multiple cystic/ necrotic areas. A thin short pedicle was visualised in the inferior aspect. Uterus was not identified properly and ovaries could not be visualised separately. A provisional diagnosis of twisted ovarian cyst was made and patient was taken up for laparotomy. 
Immediate laparotomy was done with two units of blood in hand. Abdomen was opened through midline longitudinal incision. There was blood stained peritoneal fluid. Uterus was enlarged and appeared bluish to blackish in colour.

The uterus was rotated in longitudinal axis at the junction of corpus with the cervix, by about 270 degrees clockwise (figure 1). Both ovaries and entire parametrium was bluish in colour. One ovary was placed anteriorly but towards right side and other ovary was lying posteriorly. Infundibulopelvic ligaments and uterine vessels were bluish in colour and engorged (Figure 2). Rotation was corrected after informing the anaesthetist as there are chances of hemodynamic deterioration. A very difficult total abdominal hysterectomy with bilateral salpingooophorectomy was performed. As the tissues were gangrenous difficulty was encountered while tying sutures. Drain was given in right flank which was removed on third postoperative day. Histopathological report was confirmatory of non-malignant intramural leiomyoma with necrotic changes.

DISCUSSION: The first case of uterine torsion in the non-pregnant condition was described in 19094 . Only about 200 cases have been reported in the past 100 years. ${ }^{5}$ Pathophysiology of this condition is poorly understood and unclear. Uterine body is supported by broad ligaments laterally which is a weak support while cervix has stronger support by mackenrodt and uterosacral ligaments. In our case the intramural fibroid had involved the uterus but spared the cervix. So, uterine body behaved like a heavy ball while cervix was long and thin and acted like a pedicle and isthmus behaved like a pivot around which torsion took place. This torsion had not only disturbed the pelvic anatomy but also caused acute kinking of ureter at the level of isthmus (cause of anuria in this case). During laparotomy, clear orientation of anatomy is essential in order to avoid damage to ureter.

The cause of acute pain abdomen was neurogenic due to extreme stretching of nerve fibres present in infundibulopelvic ligaments and ischaemia. Cause of shock was also neurogenic. It is extremely difficult to clinch the diagnosis on a routine ultrasound. Change in the position of a previously imaged myoma and abnormal position of ovarian vessels across the uterus using colour doppler can aid the diagnosis on ultrasound. CT finding of whorled appearance of the cervix has been described by Luk et $\mathrm{al}^{6}$ indicative of twisting of cervix. Nicholson et $\mathrm{al}^{7}$ have suggested X-shaped configuration of upper vagina on MRI as a sign to diagnose torsion, which is normally visualized as $\mathrm{H}$ shaped structure. The condition demands immediate surgical exploration. Delay in diagnosis can prove fatal as the uterus and adnexa can undergo gangrenous change.

CONCLUSION: Torsion of non-gravid uterus is potentially fatal acute abdominal condition. High degree of clinical suspicion and prompt surgical intervention is crucial in the management of such cases. Although uterine torsion is a rare condition, it should be considered as an important differential diagnosis in women with lower abdominal lump and acute abdomen. 


\section{CASE REPORT}

\section{REFERENCES:}

1. Collinet P, Narducci F, Stien L. Torsion of a nongravid uterus: an unexpected complication of an ovarian cyst. Eur J Obstet Gynecol Reprod Biol 2001; 98: 256-7.

2. Jeong YY, Kang HK, Park JG, Choi HS. CT features of uterine torsion. Eur Radiol 2003; 13 Suppl 6: L249-50.

3. Omurtag K, Session D, Brahma P, Matlack A, Roberts C. Horizontal uterine torsion in the setting of complete cervical and partial vaginal agenesis: a case report. Fertil Steril 2009; 91: 1957. e13-5.

4. Hawes CH. Acute axial torsion of the uterus. Ann Surg 1935; 102: 37-40.

5. Dua A, Fishwick K, Deverashetty B. Uterine torsion in pregnancy: a review. The Internet Journal of Gynecology and Obstetrics 2006; 6. The Internet Journal of Gynecology and Obstetrics website:

http://www.ispub.com/journal/the_internet_journal_of_gynecology_and_obstetrics/volume_6_ number_1_12/article/uterine_torsion_in_pregnancy_a_review.html. Accessed Nov 2009.

6. Luk SY, Leung JL, Cheung ML, et al. Torsion of a nongravid myomatous uterus: radiological features and literature review. Honk Kong Med J 2010; 16: 304-6.

7. Nicholson WK, Coulson CC, McCoy MC, Semelka RC. Pelvic magnetic resonance imaging in the evaluation of uterine torsion. Obstet Gynecol 1995; 85: 888-90.

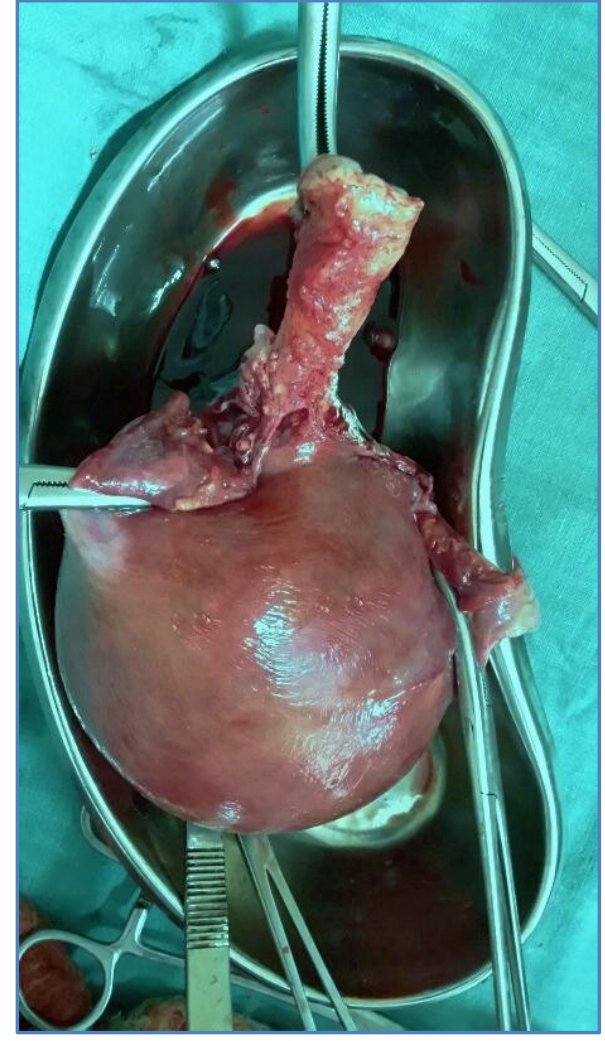

Fig. 1: Uterine torsion

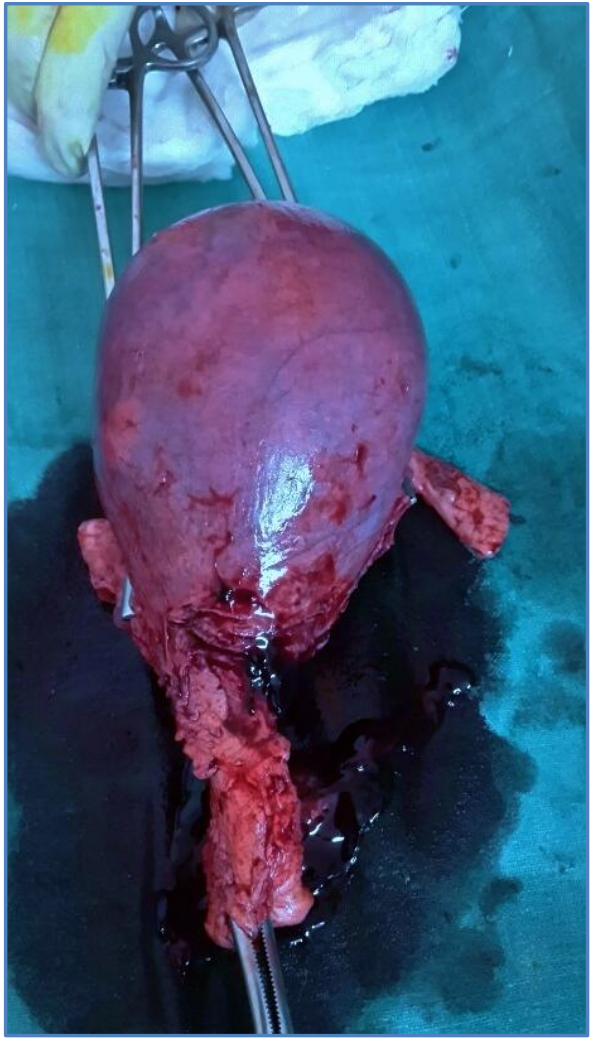

Fig. 2: Bluish discolouration due to uterine torsion 


\section{AUTHORS:}

1. Neelam Nalini

2. Bijeta

3. Jitendra Kumar Singh

\section{PARTICULARS OF CONTRIBUTORS:}

1. Assistant Professor, Department of Obstetrics and Gynaecology, Rajendra Institute of Medical Sciences (RIMS), Ranchi.

2. Consultant Gynaecologist, Department of Obstetrics and Gynaecology, Chandrama Imaging \& Health Care.

3. Chief Consultant, Department of Radiologist, Chandrama Imaging \& Health Care, Advanced Diagnostic Centre.

\section{FINANCIAL OR OTHER} COMPETING INTERESTS: None

\section{NAME ADDRESS EMAIL ID OF THE CORRESPONDING AUTHOR:}

Dr. Neelam Nalini, E-159, Sector-2, HEC, Dhurwa, Ranchi-834004, Jharkhand.

E-mail: endmasingh@gmail.com

Date of Submission: 02/02/2015. Date of Peer Review: 03/02/2015. Date of Acceptance: 16/02/2015. Date of Publishing: 23/02/2015. 